\title{
Democracia e economia solidária: limitações e potencialidades
}

Democracy and solidarity economy: limits and potentials

Uma das principais novidades no panorama político brasileiro, pós-transição democrática, é o desenvolvimento de um conjunto de práticas de economia solidária em todo o território nacional. De acordo com o Relatório de 2007, do Sistema Nacional de Informações em Economia Solidária (SIES), se entre 1951 e 1970 existiam 204 empreendimentos de economia solidária, entre 2001 e 2007 esse número chegou a 21.855 organizações.

Em nosso país, os diversos empreendimentos de economia solidária (EES), iniciaram sua atuação de maneira autônoma no tecido social, sugerindo uma ampliação da ação coletiva. Essa ampliação ocorreu porque os atores envolvidos se deslocaram de contextos de extrema vulnerabilidade social para o campo do trabalho associativo e para o campo da política formal, buscando na ação coletiva os meios de sobrevivência e os recursos para o desenvolvimento de políticas públicas próprias para o setor (Gaiger, 2004).

Entre as explicações para o vertiginoso aumento dessa proposta podemos citar o fato de que a década de 1990 foi marcada pela implantação de um conjunto de políticas socioeconômicas, tanto em nível internacional quanto no Brasil, que visaram à valorização dos mecanismos de mercado

É doutorando em Ciência Política pela Universidade Federal do Rio Grande do Sul (UFRGS, Porto Alegre-RS, Brasil).E-mail: pomlocks@gmail.com.

* É professor do Departamento e do Programa de Pós-graduação em Ciência Política (UFRGS, Porto Alegre-RS, Brasil) e pesquisador do CNPq. E-mail: alfredogugliano@hotmail.com. 
econômico enquanto modelo de reestruturação social (Cattani, 2000). Em termos de mercado de trabalho, essas políticas visaram implantar uma reestruturação produtiva, caracterizada pela extinção da economia de escala, pela flexibilização da contratação e das relações laborais e pelo uso da tecnologia informacional e eletrônica.

No caso brasileiro, como ocorreu em outros países que adotaram tais medidas, uma das principais consequências do modelo foi o aumento do desemprego e da informalidade, impulsionando o surgimento do que alguns autores chamaram de uma nova pobreza cuja principal particularidade é o "caráter aleatório da participação na vida econômica e social, pela irregularidade, precariedade e incerteza na obtenção de recursos para sobrevivência" (Cattani, 2000, p. 69).

Tendo em vista a heterogeneidade e fragmentação das classes trabalhadoras, o trabalho associativo, mesmo que marginal e constrangido por inúmeras forças na economia capitalista, começou a ganhar visibilidade e aceitação no cenário político nacional, tanto pelas potencialidades de seus mecanismos internos de participação e capacidade de garantir renda para setores vulneráveis da população, quanto pelas redes externas, criadas com entidades de apoio, movimentos sociais e pelo poder público. Dada a dimensão do fenômeno, a economia solidária se tornou uma política pública de governo, com a criação da Secretaria Nacional de Economia Solidária (SENAES), em 2003.

Como a maioria dos envolvidos na economia solidária tem optado pela ação coletiva em contextos de desemprego e precariedade, conferem-se ao movimento características de combate às desigualdades sociais (Gaiger, 2004). Tal perspectiva influenciou o desenvolvimento de um amplo leque de pesquisas, cuja revisão é recente (Leite, 2009), que abordam temas que vão desde as potencialidades econômicas dos grupos até questões culturais relativas ao empoderamento de gênero.

Entretanto, mesmo sendo rica a literatura temática publicada, consideramos que ainda existem carências de estudos que analisem os aspectos políticos envolvidos nos empreendimentos de economia solidária. Desde esse prisma, uma das problemáticas mais interessantes se relaciona com a questão das relações de poder que se desenvolvem no interior das referidas organizações, mais precisamente a democracia interna nos empreendimentos. 
É sabido que a perspectiva democrática dos empreendimentos de economia solidária é um pressuposto teórico apontado por vários autores que fundamentam a proposta de criar organismos econômicos alternativos mesmo num contexto de sociedade de mercado. Segundo Singer,

economia solidária são formas de organização econômica que adotam os valores de democracia levados às ultimas consequências dentro da área econômica. De que todos são iguais, todos têm o mesmo poder de decisão, se tiver que delegar todos votam por igual e as pessoas que os representam tem que se submeter à sua vontade senão são substituídas e são eleitas outras (Singer, 2001, p. 46, grifos nossos).

Igualmente, diversos intelectuais sublinham a existência de um vetor inovador desses empreendimentos em termos do seu funcionamento interno, oposto à tradicional empresa capitalista, hierarquizada verticalmente. Segundo a própria SENAES, a economia solidária se define como um conjunto de atividades econômicas - de produção, distribuição, consumo, poupança e crédito - organizadas sob a forma de autogestão (SENAES, 2003), conceito que, junto com o de cooperação, concede um âmago distinto a essa forma de economia (Gaiger, 2004, p. 13) ${ }^{1}$. No mesmo sentido, se afirma que a economia solidária se insere no tecido social brasileiro como uma prática diferenciada do cooperativismo e do associativismo tradicional, especificamente por causa de seu discurso e das suas lógicas de ação (Icaza, 2004).

Contudo, se no plano abstrato é clara a associação entre empreendimentos solidários e democracia, pelo menos desde o ponto de vista dos autores que defendem esse elo, são várias as dúvidas sobre como essa relação é operacionalizada na prática, isto é, no dia a dia das organizações.

Nos últimos anos vêm surgindo estudos que relativizam essas assertivas e apontam para os problemas e limitações que emergem das tentativas de democratização de estruturas laborais, especialmente a capacidade de o associa-

Apesar de o termo economia solidária e empreendimentos econômicos solidários serem as definições adotadas no cenário político e acadêmico nacional, tendo como referência a própria utilização pela Secretária Nacional de Economia Solidária (SENAES), devemos levar em conta as inúmeras divergências do seu entendimento. Outros conceitos como economia social e solidária, economia popular solidária e sócioeconomia solidária também foram criados com conteúdos e apreensões em muitos pontos opostas ao termo economia solidária, caracterizando um debate que foge aos objetivos do artigo. 
tivismo reduzir desigualdades sociais e aprofundar a democracia (Pinto, 2004; Dal Ri, 1999; Holzmann, 2000). Como explica Kerstenetzky, é importante:

apreciar adequadamente o grau de "conformismo" associado à atividade novo associativista, sobretudo em contexto de desigualdades sociais significativas. Embora a associação pareça aumentar a capacidade de autoproteção de grupos organizados, e nesse sentido acomodar uma certa visão de política, não é claro em que medida isso representaria um avanço qualitativo para a democracia (Kerstenetzky, 2003, p. 137).

Tais proposições estão diretamente relacionadas com uma nova agenda de pesquisas sobre a temática da sociedade civil baseada na ideia de que "pouco sabemos, por exemplo, das hierarquias internas e da capacidade de ação desiguais das organizações civis, da sua diferenciação funcional e das clivagens políticas e conflitos internos, em suma, do modus operandi da sociedade civil" (Lavalle et al., 2008, p. 73).

Estimulados por essas questões, o presente artigo procura apresentar os resultados de uma pesquisa realizada junto a empreendimentos de economia solidária, no ano de 2011, cujo objetivo foi analisar o desenvolvimento da democracia interna desses grupos, buscando entender como a democracia se manifesta em processos associativos e cooperativos, inseridos no contexto da economia solidária. Em outras palavras, pretendemos discutir até que ponto essa proposta, além de representar uma nova forma de organização econômica, também expressa avanços em termos da democratização da gestão e organização das relações de trabalho. Para tal, como será mais bem discutido mais adiante, nos apropriamos das categorias de democracia fraca e democracia forte utilizadas originalmente por Benjamin Barber (2003).

A pesquisa foi realizada em nove empreendimentos econômico-solidários da cidade de São Leopoldo, Região Metropolitana de Porto Alegre, analisando empreendimentos que vão desde os de pequeno porte (até 10 associados) até os de grande porte (mais de 100 associados), dedicados a atividades de reciclagem, artesanato e metalurgia, entre outras. De acordo com dados do SIES, o Rio Grande do Sul é o estado brasileiro com o maior número de empreendimentos solidários. Nesse universo, a cidade de São Leopoldo situa-se na $13^{a}$ posição em número de iniciativas no Rio Grande do Sul, destacando-se ainda em termos de organização e mobilização desses grupos, uma vez que ocorrem na cidade três fóruns autônomos dos trabalhadores: Fórum de São 
Leopoldo de Economia Solidária, Fórum de Recicladores de São Leopoldo e Fórum de Recicladores do Vale do Rio dos Sinos².

Por meio dos referidos conceitos propostos por Barber (2003), assim como do material empírico coletado, acreditamos ser possível enriquecer as análises que geralmente são realizadas sobre empreendimentos de economia solidária no Brasil. Pretendemos desse modo contribuir para o desenvolvimento das pesquisas que, em especial, analisam a economia solidária desde a perspectiva do seu impacto para a expansão da democracia na esfera das relações econômicas.

Com essa finalidade, o artigo será dividido em algumas partes. Em um primeiro momento questionamos a participação dos associados na gestão dos grupos, investigando as diversas dinâmicas estabelecidas em seus processos coletivos. Após, definimos os tipos ideais de democracia forte e fraca, situando ambos os conceitos no âmbito da economia solidária. Em um terceiro tópico, analisamos o papel das lideranças na conformação dos coletivos e concluímos sugerindo um hibridismo nas práticas democráticas operacionalizadas no âmbito da economia solidária, com uma tendência fraca e não determinística de verticalização e hierarquização das decisões coletivas.

\section{O dilema da participação nos empreendimentos solidários}

Dentro do regime legal estabelecido pelo cooperativismo em nível nacional, algumas prerrogativas de participação necessitam ser cumpridas para que uma empresa intitule-se como tal: regimento, estatuto e demais órgãos administrativos aprovados em assembleia geral e registrados em cartório, bem como realização de assembleias extraordinárias e ordinárias. Contudo, necessitamos ir mais além de uma descrição formal para compreender como as principais decisões são tomadas no ambiente de trabalho, verificando também as diferentes formas de participação e envolvimentos dos trabalhadores nos empreendimentos.

Para analisar esse tema a principal fonte de dados é o Sistema Nacional de Informações em Economia Solidária (Base SIES), onde é possível encontrar informações sobre as principais formas institucionais de participação realizadas nos EES nacionais.

Em termos metodológicos, a coleta dos dados qualitativos foi feita principalmente por meio de entrevistas semiestruturadas, observações das reuniões, das assembleias e dos fóruns e da formação de um grupo focal. 
Gráfico 1. Principais instâncias de decisão coletiva nos EES nacionais

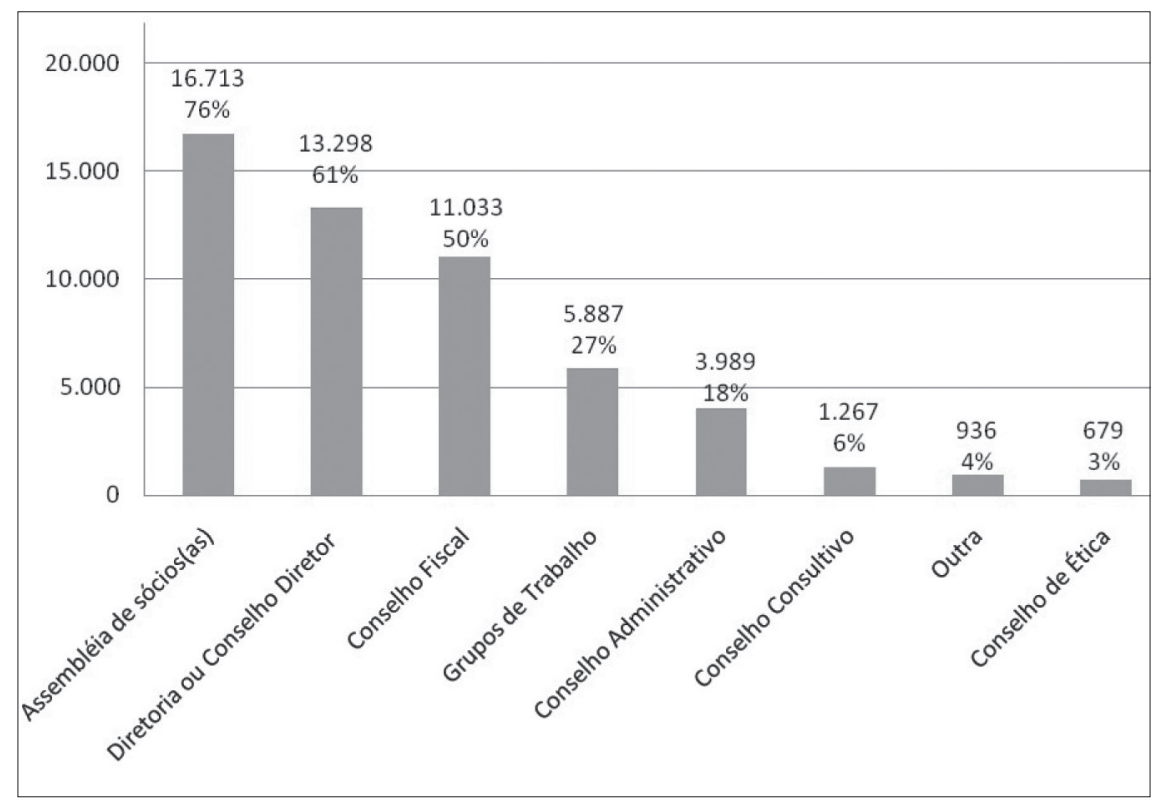

Fonte: Locks (2012).

De acordo com o gráfico acima, podemos inferir que as principais formas de participação nos empreendimentos de economia solidária em nível nacional ocorrem por meio da assembleia dos sócios (76\%), dos conselhos diretores (61\%) e dos conselhos fiscais (50\%). Com frequência menor, igualmente se encontram as reuniões de grupos de trabalho, comissões, núcleos e os conselhos administrativo, consultivo e de ética do empreendimento.

Por meio desses dados, podemos concluir que mais de $2 / 3$ dos empreendimentos analisados privilegiam uma das principais instâncias de democracia direta no seu processo de deliberação, que são as assembleias onde participam todos os sócios com o mesmo direito a voz e voto. Como, aliás, também ocorre em diversas formas de inclusão dos cidadãos na gestão pública, a centralidade do desenvolvimento de assembleias públicas abertas é valorizada por diversos autores como uma forma avançada de democratização das relações políticas (Macpherson, 1978; Pateman, 1970; Gugliano, 2004, Held, 2006) 
Essa caracterização pode ser ampliada se incluirmos na discussão dos dados também a análise da periodicidade dessas reuniões, isto é, a frequência com que os trabalhadores participam das decisões coletivas.

Gráfico 2. Periodicidade das reuniões/assembleias dos sócios nos EES nacionais

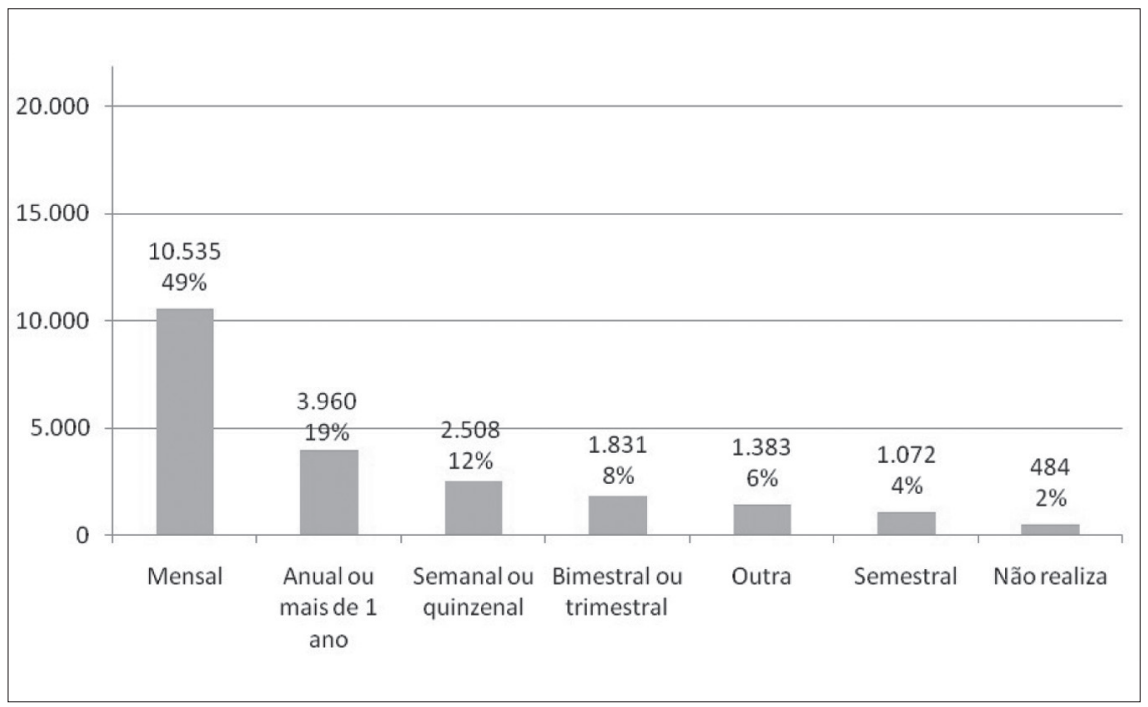

Fonte: Locks (2012).

Como vemos no gráfico anterior, dos empreendimentos nacionais que realizam assembleias ou reuniões de sócios, 19\% realizam apenas uma reunião ao ano; $4 \%$, duas reuniões; $8 \%$ realizam entre quatro e seis reuniões, e $49 \%$ levam adiante 12 reuniões. Ademais, em 6\% dos empreendimentos analisados os responsáveis ou não souberam definir a periodicidade das suas reuniões ou explicitamente não realizavam nenhuma assembleia nem reunião de sócios. Isto é, a pesquisa da SENAES aponta que a maioria dos empreendimentos de economia solidária possui uma periodicidade de reuniões que vai de semanal até bimestral/trimestral.

Em relação aos grupos pesquisados no Rio Grande do Sul, a tabela abaixo demonstra sua periodicidade das assembleias e das reuniões de associados: 
Tabela 1. Periodicidade das reuniões nos EES - São Leopoldo (2012) ${ }^{3}$

\begin{tabular}{c|c}
\hline nome do grupo & periodicidade das reuniões \\
\hline EES A & Grupo 1 (pequeno porte) \\
\hline EES B & frequência de reuniões indefinida \\
\hline EESC & reuniões semanais \\
\hline \multicolumn{2}{c}{ reuniões semanais } \\
\hline EES D & Grupo 2 (médio porte) \\
\hline EESE & reuniões semanais \\
\hline EES F & reuniões quinzenais \\
\hline EES & reuniões semanais \\
\hline EES H & reunião anual \\
\hline EESI & reuniões mensais \\
\hline
\end{tabular}

Fonte: Locks, 2012, p. 79.

De acordo com os dados apresentados anteriormente, um primeiro ponto que chama a atenção é que, no caso estudado, a frequência das reuniões é bem mais constante do que em nível nacional, predominando uma variação que vai das reuniões semanais até reuniões mensais. À primeira vista poderíamos supor que esse é um indicio de uma maior dinamicidade da participação dos trabalhadores nas decisões da empresa. Contudo, para entender a relevância dessas reuniões é essencial analisar o conteúdo das deliberações aprovadas nesses fóruns, especialmente tentando perceber se as decisões tomadas pelos trabalhadores nas assembleias, por exemplo, são significativas e relevantes na atividade laboral dos envolvidos, tema não abordado pelas pesquisas do SENAES.

No caso da pesquisa realizada nos empreendimentos solidários em São Leopoldo, fica claro que as propostas dos trabalhadores associados necessariamente não são discutidas nas reuniões institucionalizadas nos empreendimentos. De acordo com as observações realizadas nas reuniões e os depoimentos de vários associados participantes, é possível apontar que as reuniões mensais e quinzenais são utilizadas pelas direções para demonstrar

Os nomes dos empreendimentos analisados foram ocultados para resguardar a identidade dos interlocutores da pesquisa. 
a transparência das gestões dos empreendimentos para os demais trabalhadores e para a comunidade na qual estão inseridos, assim como ratificar as ações e propostas das diretorias. Na maioria das vezes o conteúdo dessas reuniões é técnico e diz respeito, principalmente, à questão financeira dos empreendimentos. Funcionando de forma vertical, como em uma prestação de contas, a diretoria expõe, por exemplo, os balanços de pagamento e o dinheiro em caixa ${ }^{4}$.

Isso nos leva a crer que não há necessariamente uma correlação entre a quantidade de reuniões e a significância das decisões, pois, uma vez que o debate político se reduz a questões administrativas, a capacidade deliberativa dos trabalhadores é baixa. Isso acaba ocasionando, como tivemos oportunidade de observar na pesquisa de campo, o desenvolvimento de mecanismos alternativos de atendimentos de demandas, nos quais necessidades são expostas e atendidas de maneira informal, isto é, sem passar pelo espaço coletivo das reuniões. Situações como essas indicam uma grande autonomia por parte das direções dos empreendimentos, fato que pode significar um desequilíbrio nas relações de poder no interior das organizações.

Contundo, é importante mencionar que também há casos nos quais decisões sobre a produção, contratação e o horário de trabalho, tomadas por meio de diretrizes coletivas, podem também viabilizar uma maior mobilização dos associados, como no caso do EES I, no qual os trabalhadores pressionaram a diretoria para que fosse feita uma votação com o intuito de mudar o coordenador de um determinado setor, uma vez que os trabalhadores estavam entrando em conflito direto com ele. Esse tipo de acontecimento implica certo conhecimento por parte dos trabalhadores dos pressupostos do trabalho em grupo e das possibilidades de mudança que o alargamento da prática democrática pode possibilitar.

Para discutir a autonomia dos associados nos empreendimentos devemos pensar também na existência de diversos fatores que constrangem as escolhas dos indivíduos quanto às decisões nas organizações. Segundo Cohen (2009), as ações falham em ser autônomas se as preferências sobre as quais um agente atua são fortemente dadas pelas circunstâncias, e não determinadas pelo próprio agente.

\footnotetext{
As informações apresentadas são fruto das observações, entrevistas e coleta de documentos nos empreendimentos de econômica solidária na cidade de São Leopoldo. Para um detalhamento maior dessas informações, sugerimos Locks (2012).
} 
De acordo com a coleta de dados efetuada, percebemos que grande parte dos empreendimentos é formada por integrantes com relações de parentesco e proximidade geográfica. Ao mesmo tempo em que isso pode levar a fortalecer laços de comunidade e pertencimento, também produz a formação de blocos internos nos empreendimentos e interfere no processo de democratização das deliberações ${ }^{5}$.

O conjunto de fatores apontados até aqui interfere no que poderíamos chamar da qualidade da democracia dos empreendimentos de economia solidária. Para analisar o desenvolvimento da democracia interna nos grupos de economia solidária optamos principalmente por utilizar e adaptar duas categorias desenvolvidas por Barber (2003): democracia fraca e democracia forte.

O conceito de democracia fraca é identificado com um modelo cuja característica principal é a restrição da cidadania ao voto e a eleição de representantes políticos, modelo comumente descrito como liberal/representativo:

A democracia liberal é então uma teoria fraca da democracia, na qual os valores democráticos são prudenciais, além de provisórios, opcionais e eventuais - dizem respeito exclusivamente a fins privados e individualistas. [...] Está mais interessada em promover a liberdade individual do que assegurar justiça pública, em fomentar interesses [privados] mais do que requerer bens coletivos, e em manter os homens separados em segurança do que trazê-los juntos de forma frutífera (Barber, 2003, p. 4, tradução nossa).

Enquanto o modelo fraco de democracia é baseado na oposição de interesses predefinidos considerados universais, o modelo forte se baseia na transformação desses interesses por meio da participação. Para isso, pressupõe a criação de uma linguagem pública por meio de um processo participativo que ajude a reformular os interesses privados num interesse público. Em Barber, a democracia forte pode ser definida como:

(...) um modelo político participativo onde os conflitos são resolvidos mediante ausência de pressupostos independentes, por meio de um processo participativo contínuo que se aproxima da autorregulação e criação de uma comunidade política capaz de transformar mutuamente indivíduos privados em cidadãos livres, e interesses privados específicos em bens públicos (Barber, 2003, p. 132, tradução nossa).

Na pesquisa de campo foi possível observar que, em alguns empreendimentos, quase $60 \%$ dos associados pertencia ao mesmo núcleo familiar. 
Sobre a temática abordada, partilhamos da opinião de que numa empresa com democracia forte os trabalhadores exercem pressão nas lideranças e também participam de maneira autônoma em escolhas significativas nas arenas formais de decisão. Por sua vez, numa democracia fraca, as escolhas e demandas dos trabalhadores não operam de maneira direta a partir de suas necessidades, mas sim a partir do reconhecimento e do encaminhamento destas por parte de uma direção que utiliza as reuniões apenas como um modo de ratificar decisões. No mesmo sentido, também podemos visualizar que determinados grupos, formados por motivos diversos dentro dos EES, podem direcionar as votações em prol de suas demandas.

Como veremos adiante, nossos dados indicam uma tendência de que a maioria dos empreendimentos de economia solidária, apesar da periodicidade das reuniões, desenvolva uma forma de democracia fraca em relação à autonomia nas decisões dos trabalhadores. Isso se deve a dois motivos. Em primeiro lugar, porque em muitos casos o predomínio de grupos familiares gera condicionantes nas tomadas de decisões, constrangendo os demais participantes do processo coletivo. Em segundo lugar, porque em alguns grupos as principais decisões não chegam nem a ser minimamente discutidas coletivamente, ferindo a autonomia do processo de deliberação no sistema de assembleias e reuniões.

\section{Democracia fraca e democracia forte}

Benjamin Barber (2003) afirma que numa democracia forte se deve entender o processo de tomada de decisão como gerador e criador de desejos públicos ou interesses em comum. A ideia central, desde esse prisma, é o desenvolvimento de uma nova dialética entre participação e comunidade, de forma que o cidadão possa ser considerado um elemento reflexivo em constante movimento de mobilização social.

Benjamin Barber (2003) observa que programas de trabalho democráticos são válidos tanto para os indivíduos quanto para a sociedade como um todo porque eles geram autossuficiência ao mesmo tempo em que constroem um senso de comunidade, ou seja, criam interesses em comum. Diante das práticas de tomada de decisão, esses interesses se caracterizam como:

[divididos entre] meu interesse e o teu. O conflito de interesses, por outro lado, é uma disputa na qual se enfrentam visões sobre o único futuro possível. Apesar da 
incompatibilidade dos nossos desejos, o mundo que queremos que exista só pode ser um mundo - uma área comum em que nossos desejos e interesses serão satisfeitos ou frustrados (Barber, 2003, p. 201, tradução nossa).

Essa visão está intimamente ligada à concepção de cidadania do referido autor, posto que, para Barber (2003), a democracia não é nem o governo da maioria nem o governo dos representantes da maioria, mas os cidadãos, unidos pelos interesses que possuem em comum, que governam.

Contudo, um pressuposto para a produção de interesses comuns é a democratização da fala, pois muitas vezes indivíduos centralizam a comunicação, por sua capacidade de oratória, fazendo com que os menos privilegiados deixem de lado as suas expressões e demandas em prol de um determinado bem comum. Em consequência, o silêncio dos oprimidos pode remover demandas consideradas problemáticas dos processos coletivos, restringindo a agenda na tomada de decisões frente à necessidade de barrar qualquer possibilidade de abalar o suposto bem comum.

Por meio dessas reflexões, podemos pensar o caso dos empreendimentos de economia solidária, uma vez que em sua maioria são formados por parentes, amigos ou vizinhos. Tal relacionamento, que conecta a esfera da vida privada e a da vida pública, proporciona um ambiente diferente daquele impresso em boa parte das empresas de cunho privado. Notamos, durante a pesquisa empírica, que, se por um lado há nos empreendimentos a necessidade do discurso e da prática cooperativa e democrática, por outro, as relações de proximidade, familiares e de vizinhança, podem gerar tanto relações de pertencimento e comunidade quanto de hierarquização e subordinação. Essas diferentes lógicas que podem emergir, por sua vez, afetam significativamente as percepções das pessoas inseridas em um processo de tomada de decisão e, consequentemente, limitam a construção coletiva.

Para analisar como os interesses são formados nos empreendimentos, foi necessário ir além dos próprios discursos dos trabalhadores, confrontando falas e investigando a estrutura de oportunidades para a participação nos grupos. Usamos como exemplo o EES B, em que o presidente tira da reciclagem a principal fonte de renda de sua família, que, por sua vez, constitui $50 \%$ do total de trabalhadores do empreendimento. Esse relacionamento advindo da esfera de relações privadas da família, quan- 
do reproduzido na associação diante dos demais trabalhadores, reflete e reforça as estruturas de poder patriarcais de nossa sociedade, uma vez que o pai da família é o presidente/dirigente que cuida da administração geral da empresa, enquanto os demais estão a ele subjugados na hierarquia funcional do grupo.

Sobre isso ainda é interessante sublinhar que, embora a maioria dos trabalhadores da economia solidária de São Leopoldo sejam mulheres (Base SIES), somente em três das nove associações e cooperativas analisadas elas ocupam cargos de direção, o que nos indica que o mantenimento das estruturas patriarcais também acirra desigualdades de gênero nos empreendimentos solidários. Dentro dessa perspectiva, algumas análises feitas a partir da Base SIES também corroboram nossa argumentação, apontando que a presença feminina na economia solidária ainda se pauta pela divisão sexual do trabalho (Souza, 2011; Sucupira e Braga, 2010). Tais afirmações se fundamentam no fato de que os grupos formados somente por mulheres tendem a ter uma renda menor do que os grupos formados somente por homens, e ainda, que os empreendimentos de mulheres são, em sua maioria, grupos informais e associações centrados nas áreas de confecção têxtil, costura, e alimentação, cozinha.

Relaciona-se com isso a forma como os conflitos entre os associados são tratados no interior dos empreendimentos solidários. Em uma democracia fraca o conflito entre interesses concorrentes é valorizado como uma opção individual que deve ser respeitada. As opiniões e os julgamentos são predefinidos na esfera privada e, uma vez que a política se assemelha ao mercado econômico, cabe aos políticos profissionais captar a diversidade de opções individuais para reorientá-los e agregá-los em ações públicas. Assim sendo, a mobilização e o conflito social são considerados prejudiciais para as instituições, que seriam abaladas em sua credibilidade, com o risco de paralisia decisória se tornando imanente e sendo necessário que os dirigentes políticos administrassem as diferenças de forma a não ferir a hierarquia administrativa.

Por oposição, em uma democracia forte, o conflito deve ser reorientado por valores cooperativos. Situando as disputas no início e no meio do processo de debate político, Barber (2003) visa à transformação das divergências individuais em cooperação por meio da deliberação pública, da participação e da educação cívica, temas centrais de sua argumentação. Indissociável 
do conflito está a possibilidade de dar voz àqueles indivíduos discordantes durante o processo de deliberação, garantindo o respeito à desconfiança, ao dissenso e à oposição de ideias.

De acordo com esses pressupostos, entendemos que os grupos pesquisados, em sua grande maioria, apresentam dificuldades em lidar com o conflito, esteja ele situado no início, no meio ou no fim do processo deliberativo. Uma maneira de captar essa dificuldade foi investigando a rotatividade nos principais cargos dos empreendimentos. Por si só, a quantidade de empreendimentos que tiveram rotatividade nos cargos já apresenta um dado interessante para análise, uma vez que apenas quatro, dos nove empreendimentos analisados, apresentam alterações nos cargos de direção em um período de mais de dez anos de consolidação dos grupos. A esse respeito chama a atenção o fato de que, em três das quatro cooperativas e associações que mudaram a presidência do empreendimento, os antigos gestores acabaram por desistir e abandonaram o empreendimento. Isto é, a mudança administrativa foi seguida de uma ruptura entre os membros do grupo, especificamente nos casos de cooperativas em que a mudança é obrigatória.

Com esses dados, temos exemplos que apontam para a possibilidade de que o conflito nos empreendimentos e a possibilidade de dar voz aos sujeitos discordantes é um assunto delicado, notadamente quando visualizado na prática diária dos trabalhadores. Nesses casos o conflito expresso pela mudança de direções não resulta em cooperação, como pretende Barber (2003), mas sim em uma cisão própria de modelos de democracia fraca, pois os representantes dos grupos rejeitam o retorno "ao chão da fábrica", procurando alternativas de trabalho.

Em relação aos cinco empreendimentos em que não houve mudanças de direção, foi possível observar em alguns casos o engessamento de lideranças em postos de comando, considerando que, uma vez situadas nos cargos diretivos, permanecem ali por tempo indeterminado e impedem a ascensão de outros membros. Essa prática, também possibilitada pela flexibilidade jurídica de associações e grupos informais, dificulta o surgimento de movimentos de oposição. Tal engessamento, seguido de uma postura autoritária em relação às decisões coletivas, acaba por condicionar o envolvimento dos trabalhadores, que, se por um lado demonstram pouca 
participação em relação ao processo de deliberação dos empreendimentos, por outro lado são estimulados a continuar com essa postura.

\section{O papel das lideranças}

Uma questão que foi constante na nossa pesquisa foi a percepção do papel preponderante dos dirigentes dos empreendimentos solidários no processo deliberativo envolvendo os trabalhadores. Consequentemente, para entender a democracia na economia solidária é essencial compreender as características das suas lideranças.

Em geral, há uma tendência em associar economia solidária com formas avançadas de gestão democrática, nas quais

o líder solidário (qualquer trabalhador/a no momento em que assume esse papel, não somente o líder formal) possui competências necessárias para a execução da tarefa (comunicação, conhecimento técnico e educacional, empatia, confiança, paciência, transparência, etc.); toma as decisões democraticamente em reuniões; representa o empreendimento nos contextos externos e articula-se politicamente, além de também operacionalizar o processo produtivo igualitariamente com os demais associados (Veronese e Scholz, 2011, p. 15).

De um modo geral, a pesquisa realizada aponta para as limitações dessa caracterização de liderança. Por meio da tabela abaixo podemos inferir que as lideranças eleitas dos empreendimentos, na medida em que estes vão crescendo em proporção, se deslocam para postos administrativos, distanciando-se em certa medida dos demais trabalhadores. Tal faceta dos grupos abre uma agenda de pesquisa relacionada ao próprio tamanho dos empreendimentos e à possibilidade de grupos muito grandes adotarem a autogestão, lema central da economia solidária. Segundo Lorena Holzmann, estudando o caso de uma cooperativa no Rio Grande do Sul,

a divisão do trabalho entre trabalhadores que fazem (manuais) e trabalhadores que pensam (intelectuais) e as relações de dominação/subordinação existentes entre eles se renovaram e foram consentidas na esfera do discurso, assegurando aos que dominavam as formas sancionadas do discurso a condução do processo de tomada de decisões (Holzmann, 2000, p. 54). 
Tabela 2. Posição das lideranças em relação ao coletivo

\begin{tabular}{|c|c|}
\hline nome do grupo & tarefas dos líderes \\
\hline \multicolumn{2}{|c|}{ Grupo 1 (pequeno porte) - 5 a 9 Sócios } \\
\hline EES A & gestor/executor \\
\hline EES B & gestor/executor \\
\hline EESC & gestor/executor \\
\hline \multicolumn{2}{|c|}{ Grupo 2 (médio porte) - 10 a 29 sócios } \\
\hline EES D & gestor/executor \\
\hline EESE & gestor/executor \\
\hline EES F & gestor/executor \\
\hline \multicolumn{2}{|c|}{ Grupo 3 (grande porte) - mais de 30 sócios } \\
\hline EES G & gestor \\
\hline EESH & gestor \\
\hline EESI & gestor \\
\hline
\end{tabular}

Fonte: Locks (2012, p. 108).

Além disso, verificamos a eminência de lideranças que circulavam entre uma filiação a partido político, movimento social ou esfera governamental, exercendo o que a literatura chama de tripla militância (Tatagiba e Teixeira, 2007). Circulando em diferentes arenas políticas, essa liderança faz a intermediação entre o aparato institucional do Estado, as demandas do movimento e as demandas do empreendimento do qual faz parte. Destacamos que, durante a pesquisa empírica, encontramos duas lideranças de diferentes empreendimentos que fizeram o percurso movimento/partido/ governo. Contudo, de acordo com os depoimentos coletados, cada um fez o percurso de maneira diferente.

Enquanto uma liderança foi do partido político ao movimento social em busca de recursos políticos, ingressando posteriormente na administração pública como cargo de confiança no executivo municipal, a outra liderança exerceu a tripla militância de forma simultânea: dirigente de empreendimento/dirigente de entidade de movimento social/cargo de confiança no Poder Executivo municipal.

Além dos casos de tripla militância, que expressam um determinado circuito político-institucional, em sua maioria as lideranças das associações encaixam-se nos casos de dupla militância, envolvendo movimentos sociais 
ou partidos políticos. Essas lideranças, assim, respondem não só pelo movimento mas também às pressões dos partidos políticos e dos governos.

Uma vez que são participantes ativos das reuniões de partidos ou de atividades de movimentos sociais, essas lideranças tendem a dirigir o grupo devido a sua distinção ideológica e suas redes, captando recursos necessários em prol de determinada visibilidade política seja para o grupo ou para si próprios. Por sua vez, como foi possível observar na maioria dos empreendimentos analisados, o grupo se torna dependente dos laços e das funções exercidas por seus dirigentes.

Essa relação dos dirigentes de empreendimentos de economia solidária com partidos políticos, movimentos sociais e governo não só expressam um processo de profissionalização da militância política (Tatagiba, 2010; Cruz, 2007), como também representam uma forte tendência de vinculação dos empreendimentos a outras redes sociais, especialmente vinculadas aos movimentos sociais e partidos políticos.

Contudo, de acordo com a pesquisa feita, percebemos que existem ambiguidades no discurso dos atores que se situam entre movimentos sociais diversos, uma vez que seus interesses também podem ser predefinidos nesses movimentos, dificultando a construção com o coletivo de associados. Por esse viés, esses atores já inseridos em movimentos sociais ou em partidos, ao entrarem na economia solidária, destoam em termos de oratória e militância dos demais trabalhadores, que em sua maioria somente estão em busca de novas opções de emprego. Esses valores e crenças dos militantes e dos não militantes igualmente caracterizam situações de permuta recíproca De acordo com Mansbridge:

[O]s movimentos sociais trabalham tanto para mudar o modo de pensar das pessoas quanto para pressionar os governos para a implementação de leis. A conversação política intencional dos ativistas políticos tanto influencia quanto é influenciada pela conversação cotidiana dos não ativistas [...]. Não ativistas afetam o que os ativistas dizem e pensam [...] por responderem a essas ofertas demonstrando entendimento ou confusão, interesse ou enfado, apropriação ou rejeição [...] testam novas e velhas ideias contra suas realidades diárias (Mansbridge, 2009, p. 210).

Essa diversidade de problemáticas nos mostra a quantidade de fatores que podem influir nos processos coletivos de tomada de decisão e coloca a economia solidária e o associativismo brasileiro como um campo ainda em construção, portanto indefinido e incipiente. 


\section{Conclusões}

Neste trabalho nosso objetivo foi analisar a problemática da democracia a partir da análise dos grupos informais, associações e cooperativas dentro do que atualmente denominamos de economia solidária. Mesmo tendo ficado restritos ao estudo de experiências em nível de município gaúcho, cremos que os dados apresentados contribuem para compreender situações semelhantes que ocorrem em todo o país, tendo em vista que a problemática das relações de poder no interior das EES é uma problemática de interesse nacional e internacional. Por meio da discussão apresentada, estabelecemos algumas considerações relevantes para o debate nacional sobre as possibilidades e limitações da democracia nesses ambientes.

De um modo geral, constatamos, a partir da análise dos espaços deliberativos em nove empreendimentos de economia solidária, que em boa parte dos grupos analisados, as práticas politicas desenvolvidas internamente estiveram muito próximas do que denominamos democracia fraca, caracterizada pela emergência de uma liderança forte com altos níveis de autonomia, muitas vezes ligada a partidos políticos ou a movimentos sociais de cunho geral. A participação e o envolvimento dos trabalhadores, no que diz respeito às demandas gerais, usualmente são reduzidos. As tomadas de decisões são normalmente realizadas por uma elite dirigente que usa a comunicação de modo esporádico e autoritário, restringindo a autonomia dos participantes, velando os conflitos e atomizando os indivíduos durante o processo coletivo.

Foi possível observar também o engessamento de lideranças em postos de comando, considerando que, uma vez situadas nos cargos diretivos, permanecem ali por tempo indeterminado e impedem a ascensão de outros membros da associação, dificultando o surgimento de movimentos de oposição. Tal engessamento, seguido de uma postura autoritária em relação às decisões coletivas, acaba por condicionar o envolvimento dos trabalhadores que, se por um lado demonstram pouca participação em relação ao processo de deliberação dos empreendimentos, por outro lado são estimulados a continuar com essa postura.

No entanto, também encontramos, em menor escala, alguns exemplos de práticas de tomada de decisão mais igualitárias, cujas dinâmicas internas são próximas ao que denominamos de democracia forte. São casos nos quais as lideranças têm uma trajetória de maior envolvimento com os trabalhado- 
res do empreendimento econômico solidário, as reuniões são frequentes e existe uma grande capacidade de mobilização dos trabalhadores no tocante às suas reivindicações. Nessas experiências, os trabalhadores apresentaram capacidade de autogerir projetos, assim como de pressionar os gestores da empresa para o atendimento de propostas discutidas pela base. O fluxo de alternância de dirigentes do empreendimento também é mais ágil, não sendo raros os casos de lideranças substituídas devido à má administração ou centralização excessiva, bem como de pressões exercidas pelos trabalhadores em prol de suas demandas.

Destacamos que, nesses casos, a participação tende a ser cobrada e exercida semanalmente tanto por parte dos próprios dirigentes quanto por parte de equipes técnicas de apoiadores, encurtando a distância entre dirigentes/ dirigidos e estimulando o surgimento de uma tendência maior à participação por parte dos trabalhadores. Apesar disso, sugerimos que há um hibridismo nas práticas democráticas operacionalizadas no âmbito da economia solidária, com uma tendência fraca e não determinística de verticalização e hierarquização das decisões coletivas.

Para finalizar, cabe destacar que compartilhamos a ideia de que a economia solidária e o associativismo possibilitam o estabelecimento de relações mais justas no ambiente de trabalho, em que a possibilidade da mudança de padrões vigentes por meio de procedimentos democráticos está presente. Contudo, apesar desse avanço em termos de mudanças nas relações de trabalho, ainda há muito a caminhar no que diz respeito à democratização das suas estruturas de decisão, tendo em vista que boa parte dos grupos ainda carece de práticas democráticas robustas. Esse é, portanto, um ponto que merece ser aprofundado entre os empreendimentos de economia solidária e os pesquisadores que pensam em modelos alternativos de organização de um sistema democrático de produção econômica.

\section{Referências}

BARBER, Benjamin (2003). Strong democracy participatory politics for a new age. Berkeley: University of California Press.

CATTANI, Antônio David (2000). Trabalho e autonomia. Petrópolis: Vozes. COHEN, Joshua (2009). "Deliberação e legitimidade democrática”, em MARQUES, Angela C. Salgueira (org.). A deliberação pública e suas dimensões sociais, políticas e comunicativas. Belo Horizonte: Autêntica. 
CRUZ, Gisele R. (2007). “Associativismo e democratização da sociedade: limites e possibilidades". Comunicação \& Política, n. 24, p. 89-114.

DAL RI, Neusa Maria (org.) (1999). Economia solidária: o desafio da democratização das relações de trabalho. São Paulo: Universidade Aberta. GAIGER, Luiz Inácio (org.) (2004). Sentidos e experiências da economia solidária no Brasil. Porto Alegre: Editora UFRGS.

GUGLIANO, Alfredo Alejandro (2004). "Democracia, participação e deliberação". Civitas, v. 4, n. 2, p. 257-283.

HELD, David (2006). Models of democracy. Cambridge: Polity.

HOLZMANN, Lorena (2000). "Gestão cooperativa: limites e obstáculos à participação democrática”, em SINGER, Paul \& SOUZA, André Ricardo de (orgs.). A economia solidária no Brasil: a autogestão como resposta ao desemprego. São Paulo: Contexto.

ICAZA, Ana Mercedez Sarria (2004). "Solidariedade, autogestão e cidadania: mapeando a economia solidária no Rio Grande do Sul”, em GAIGER, Luiz Inácio (org.). Sentidos e experiências da economia solidária no Brasil. Porto Alegre: Editora UFRGS.

KERSTENETZKY, Célia Lessa (2003). "Sobre associativismo, desigualdades e democracia”. Revista Brasileira de Ciências Sociais, n. 18, p. 131-142.

LAVALLE, Adrian Gurza; CASTELLO, Graziela \& BICHIR, Renata (2008). "Atores periféricos na sociedade civil: redes e centralidades de organizações em São Paulo”. Revista Brasileira de Ciências Sociais, n. 23, p.73-96.

LEITE, Marcia de Paula (2009). "A economia solidária e o trabalho associativo: teorias e realidades". Revista Brasileira de Ciências Sociais, n. 24 , p. 31-51.

LOCKS, Pompilio (2012). Democracia e economia solidária: uma análise dos processos de tomada de decisão em empreendimentos econômicos solidários. Dissertação (mestrado) em Ciência Política. Porto Alegre: Universidade Federal do Rio Grande do Sul.

MACPHERSON, C. B. (1978). A democracia liberal: origens e evoluções. Rio de Janeiro: Zahar.

MANSBRIDGE, Jane (2009). "A conversação cotidiana no sistema deliberativo", em MARQUES, Angela C. Salgueira (org.). A deliberação pública e suas dimensões sociais, políticas e comunicativas. Belo Horizonte: Autêntica. 
PATEMAN, Carole (1970). Participação e teoria democrática. Rio de Janeiro: Paz e Terra.

PINTO, João Roberto Lopes (2004). Economia solidária: um elogio à associação em tempos de crise. Tese (doutorado) em Ciência Política. Rio de Janeiro: IUPERJ.

SINGER, Paul (2011). Economia solidária: possibilidades e desafios. Disponível em: http://www.logolinkla.org/conteudos/documentos/PaulSinger_ port(1).pdf. Acessado em 18 out 2012.

SENAES (2003). Economia solidária em desenvolvimento. Brasília: SENAE/MTE.

SOUZA, André Ricardo (2011). "Um exame da economia solidária”. Otra Economía, v. 5, n. 9, p. 173-184.

SUCUPIRA, Grazielle Silva \& BRAGA, Marcelo José (2010). "Empreendimentos de economia solidária e discriminação de gênero: uma abordagem econométrica”, em FERREIRA, Marco Aurélio Marques; EMMENDOERFER, Magnus Luiz \& GAVA, Rodrigo (orgs.). Administração pública, gestão social e economia solidária: avanços e desafios. Viçosa: Editora UFV.

TATAGIBA, Luciana \& TEIXEIRA, Ana. C. (2007). "O papel do CMH na política de habitação em São Paulo”, em CYMBALISTA, Renato et al. (orgs.). Habitação: controle social e política pública. São Paulo: Instituto Pólis.

TATAGIBA, Luciana (2010). "Desafios da relação entre movimentos sociais e instituições políticas”. Colombia Internacional, n. 71, p. 63-83.

VERONESE, Marília. V. \& SCHOLZ, Robinson H. (2011). “O processo emergência da liderança solidária compartilhada: um estudo de casos múltiplos". Trabalho apresentado no XI Congresso Luso-Afro Brasileiro de Ciências Sociais. Salvador, 7 a 10 de agosto.

\section{Resumo}

Nesse trabalho realizamos uma pesquisa com o intuito de aprofundar nossa compreensão sobre a operacionalização da democracia no âmbito da economia solidária. Enquanto para um segmento da literatura acadêmica as associações produtivas contrariam a empresa capitalista e aprofundam a democracia, outro lado rejeita essas possibilidades. Negando esse binarismo, por meio de análises qualitativas, junto a nove grupos da Região Metropolitana de Porto Alegre, concluímos que há um hibridismo em relação a essas práticas 
com uma tendência fraca e não determinística de verticalização e hierarquização, causada por fatores múltiplos.

Palavras-chave: democracia; economia solidária; participação; trabalho.

\begin{abstract}
In this work we develop a research in order to deepen our understanding of the operation of democracy within the solidarity economy. While a segment of academic literature production associations oppose the productive capitalist enterprise and deepen democracy, the other side rejects those possibilities. Denying this binary, through qualitative analysis, working with nine groups in the metropolitan area of Porto Alegre, we conclude that there is some hybridism in relation to these practices with a weak and non-deterministic trend to vertizalization and hierarchization that is caused by several factors.
\end{abstract}

Key words: democracy; solidarity economy; participation; work.

Recebido em $1^{\circ}$ de junho de 2012.

Aprovado em 6 de setembro de 2012. 